\title{
Niña Ciervo en la pedagogía poética de Gabriela Mistral
}

\author{
Stella Salinero ${ }^{1}$ \\ “iqué bien entender tú el alma \\ y yo acordarme del cuerpo!" \\ Poema de Chile (Hallazgo).
}

Intentaremos analizar en este texto las intensas relaciones que Gabriela Mistral teje en torno a las figuras de la niña/o y el ciervo. Figuras que se plantean en duplicidad, como parejas de un mismo sistema de significación. La motivación es capturar la potencialidad crítica que éstas entrañan y la innovación que portan y entregan tanto al discurso poético como al pedagógico, al mismo tiempo que su dimensión simbólica y cultural.

Nuestra lectura de la obra de Gabriela Mistral se encausa hacia la búsqueda de nuevos significados de una obra entendida como compleja, plural y en constante diálogo con la sociedad, en asuntos políticos, estéticos y pedagógicos. Por este motivo planteamos la figura de niña ciervo como una alegoría del proceso de aprendizaje al interior del discurso mistraliano.

El encantamiento del mundo experimentado por Gabriela Mistral en la niñez hace eco en su poesía y prosa. La naturaleza se personaliza haciendo gala de múltiples adjetivos. Esta relación tan íntima la acompañará por el resto de su vida, escribe... "tanto me da su persona maravillosa que hasta pretendo mantener con ella algo parecido a un coloquio" (VV. AA., 1997, 124). El contacto con la naturaleza es crucial para la poeta, sobre todo en la infancia, lo que permite mantener los sentidos limpios ${ }^{2}$ y desarrollar una conciencia y conocimiento pleno del mundo a partir de la experiencia viva y concreta del juego. Para Mistral el niño/a tiene un lugar primordial en el progreso de la humanidad; "cada niño trae una esperanza llena de fuerza y de misterio a las colectividades caducas que son las nuestras, hasta en esa fresca la 
América" (Scarpa, 2005, 62). La autora expone que el niño/a es un ser ávido para captar el mundo en su dimensión profunda. En un artículo denominado "Elogio del Niño" (1928), Mistral describe la manera particular que tiene éste de relacionarse con el mundo y las facultades particulares que posee. Escribe, "en su embotamiento y azoro del mundo, él tiene razón que le sobre: así como lo ve, así es, una inmensa calcomanía caliente y una Tarasca feroz" (Scarpa, 2005, 55). Desde esta perspectiva emerge Niña Ciervo, visión que se proyecta hacia una crítica a la educación y a la razón homogeneizadora, posibilitando una pedagogía poética que integra y valora la subjetividad y la experiencia concreta del niño en el proceso de aprendizaje, planteando un nuevo modo de relación entre éste y la maestra.

\section{El porqué de Niña Ciervo}

Hemos extraído el nombre Niña Ciervo del Poema de Chile que, dicho a grandes rasgos, problematiza la cuestión de la identidad cultural a partir del viaje por Chile de una mujer que retorna como fantasma (la mama) acompañada de un niño-ciervo que encuentra en unos matorrales. Hemos decidido cambiar el género de masculino a femenino, porque si bien en el Poema el niño atacameño representa parte de lo negado por el discurso histórico-cultural chileno (el indígena), hemos querido remarcar la diferencia sexual en tanto otra marca de marginalidad y subversión. Pero también hay otro motivo que nos moviliza a desplazar al niño-ciervo hacia el género femenino, esto es, la coincidencia que Mistral traza entre niño y mujer como seres diferentes. Coincidencia que se construye también a partir de la situación de excluidos del discurso de la racionalidad occidental. Reflexiona: "Se me ocurre a veces que sí es cierto lo que han dicho de nosotras las mujeres, con ánimo de ofendernos y sin ofendernos: que somos niños" (Scarpa, 1978, 89). Mistral despoja ese prejuicio de su connotación negativa y le otorga una positiva. Continúa diciendo: "Puede ser; sólo que unos niños vueltos más concientes que los otros; unos niños padecidos y más alertas, que tendríamos en este mundo cierto encargo que no se ha dicho o por lo menos precisado" (Scarpa, 1978, 89). Hay más similitudes entre ambos, por ejemplo la "locura" (ésta se presenta como 
la imposibilidad de entender lo diferente, lo otro por parte del discurso hegemónico); "el niño no es loco, y si lo es, mejor anda y mejor vive así" (Scarpa, 1978, 55). Esta estrategia indica la diferencia que entraña este sujeto dentro de la lógica dominante y marca un espacio de liberación, en palabras de Marjorie Agosín "la condición de locura permite un claro acceso hacia la posibilidad de la libertad y a la vez, la posibilidad de subvertir el orden de los que juzgan inhumanamente" (VV. AA., 1997, 161).

Niña ciervo

"El que más sabe es el indio; el que oye mejor, el ciervo; y yo trato con estos hijos por gracia de ambos, sabiendo". Poema de Chile (Palmas de Ocoa).

Gabriela Mistral elabora, a partir del mundo de la fábula, una imagen poética del niño/a que nos sorprende por lo acertada, fascinante y bella, y por lo que nos ayuda a comprenderlos en su singularidad. A partir de la imagen del ciervo emerge la dimensión simbólica del niño. En Poema de Chile Mistral realiza esta simbiosis entre niño y ciervo: "Naciste en palmo último/ de los incas, Niño-Ciervo" (Quezada, 2001, 256). Para Gabriela el ciervo es un animal emparentado con lo divino, poseedor de una sensibilidad fina que capta aquello que está más allá de lo aparente. Escribe en Recado de las voces infantiles:

\footnotetext{
“Estos niños míos, estos niños de niebla y aire, casi irreales en su belleza menuda y pobre, tienen algo de cervatillos que aprontan el casco y giran el ojo en husmeo de cazador (...) hay por eso mismo, que sorprenderlos en el canto como a los ciervos en el bebedero: sin ruido de hojas ni aspavientos de presencia. Entonces se darán enteros en su ricura elemental" (Scarpa, 2005, 60).
}

Los niños poseen una riqueza, un saber, que los adultos no comprenden a cabalidad. Para captarlo hay que ser observador y respetuoso de su propia lógica. Si bien podemos pensar que se refiere a los niños en general, en la frase se refiere a los niños 
(pobres) de Latinoamérica: “A estos mis niños - porque tan míos los siento como cosa parida- me los he visto y bebido por estos recodos y senderillos de América que siempre, al verlos al fondo de sus voces, se me antojan también algo como la infancia de la Tierra, para que mejor rimen en el ejercicio de su travesura y de su asombro" (Scarpa, 2005, 60). Resalta su fragilidad y su extrema sensibilidad, su espontaneidad y capacidad de gozar las cosas sencillas, pero también su inteligencia, belleza y gracia.

En un artículo denominado "Menos cóndor y más huemul" (1926), Mistral llama a atender los valores que encarna el mamífero de nuestro escudo nacional, aduciendo que mucho se ha dicho sobre el cóndor y olvidado ha quedado el huemul. En el texto éste se presenta como una posible otra forma de ser: "El huemul quiere decir la sensibilidad de una raza: sentidos finos: el oído delicado, inteligencia vigilante, gracia. $Y$ todo eso es defensa, espolones invisibles pero eficaces del espíritu" (Pérez, 2005, 36). Asimila su significado con lo femenino, cruzándose así con lo que hemos denominado como propio del niño/a. Pensamos que este cruce entraña la necesidad de integrar una visión diferente a lo que se ha entendido como lo humano (es decir masculino), que surge como una urgencia de vez en vez por sus escritos, con la intención de imaginar otra(s) forma(s) de ser que se aleja(n) del sistema simbólico androcéntrico, dentro de las que se podrían encontrar la madre/maestra y niña ciervo.

\section{Descripción concepto mistraliano de niño/a}

La concepción del niño/a es compleja y política; se reconoce que el niño/a tiene una razón propia (negada por un discurso que lo mantiene sin capacidad), y luego, al escribir los Derechos del niño (1927), se sostiene la responsabilidad que tiene la sociedad sobre él, asegurando su bienestar y desarrollo integral. La forma que tiene el niño/a de experimentar el mundo es de por sí creadora para la poeta, abre los secretos de las cosas y los brinda a las emociones y a los sentidos. "Ahí va borracho de aire y de luz, con el pelo suelto como una crin, y otra vez tiene razón, porque todo se vuelve vino para unos sentidos limpios y en vacaciones" (Scarpa, 2005, 55). Para la autora el conocimiento del mundo es 
una búsqueda que el niño/a tiene que hacer por sí mismo/a. El niño/a "va derecho a lo caliente, lo ágil, y ningún mañoso le convence con el monigote o pelele; todos sus sentidos, parecen pájaros alertas, saben de un golpe, al tocar, al oír, o al ver si aquello que le dan es pasto fresco" (Scarpa, 2005, 279). Pensamos que por este motivo es tan recurrente el término hallazgo o albricia en sus poemas y prosas, ya que estos señalan, por un lado, la dimensión cognoscitiva primordial del juego en la relación del niño/a con su entorno y por otro, una forma poética de descubrir las cosas. "El niño acaba el día como si hubiese cosechado cincuenta aventuras y es verdad que las tuvo, puesto que las arreó, y las luchó, sentado en una piedra o al dormirse" (Scarpa, 2005, 56).

Mistral sostiene que el niño/a "inventa tanto como aprende, no es verdad que lo imite todo" (Scarpa, 2005, 55). La tarea de la maestra es estimular al niño/a, guiarlo y dejar lugar a sus intuiciones. Al contrario de lo que aún hoy se reproduce en las escuelas de nuestro país, al niño/a se le reconoce una forma particular de saber, como también un proceso, y no solamente receptor pasivo de información mecanizada. Para Mistral todos nacemos con instinto poético: “La poesía es en mí sencillamente un rezago, un sedimento de la infancia sumergida" (Olea y Fariña, 1997, 34), pero éste se pierde con el tiempo, ya que hemos perdido una relación auténtica con la vida, debido a las deformaciones producidas en el individuo por la enseñanza (disciplinaria) y la sociedad. Sobre esto escribe: “Quien se vuelve máquina de repeticiones es el hombre hecho y derecho" (Scarpa, 2005, 56).

\section{Pedagogía Poética}

Es indudable que la visión diferente que tiene Mistral sobre el niño/a y la educación es fruto de su sensibilidad de poeta; eso es crucial a nuestro parecer para elaborar un pensamiento reflexivo que privilegie la integración de lo estético en el proceso educativo.

La Pedagogía Poética es un concepto que resignifica el proceso educativo como algo fluido, vivo, múltiple, incorporando la sensibilidad como factor unificador a la racionalidad (confluencia de lo real y lo imaginario); apoyando esta idea Mistral escribe so- 
bre el niño/a, "el mundo visible y el otro no los tiene separados el buen sabedor" (Scarpa, 2005, 56). Realza los cinco sentidos, pues todos están comprometidos para aprehender el mundo, desvinculándose de la tradición occidental que privilegia ante todo la visión. La pedagogía convencional imprime prejuicios, reproduce convenciones y conceptos erróneos sobre el niño/a, lo que finalmente afecta su (de) formación. Mistral critica la mecanización de la enseñanza dada por el método información / imposición, respuesta automática. En Poesía infantil y folklore (1935) expresa su convicción de la dimensión educativa de la estética; "les hablaría a ustedes de cómo siento yo que la belleza es tan educadora como la lógica" (Scarpa, 2005, 275). Noción que hoy consideramos necesaria para reencantar la enseñanza y devolverle su potencial liberador de práctica significativa, que se ha visto negado por la supremacía de la racionalidad económica. En una Pedagogía Poética el niño/ a se convierte en protagonista de su proceso de aprendizaje, aportando con su propia forma de ser y su visión del mundo.

Un concepto interesante en la poética de Mistral es el de albricia, pues supone un regalo que se entrega a quien porta una buena noticia; el conocimiento a través de la belleza, en este caso. Una pedagogía poética tendría como objetivo cultivar e incentivar la libertad en el individuo, el desarrollo de sus capacidades reflexivas y estéticas. Para Mistral esta concepción no forzaría nada, sino que vendría siendo natural en el niño/a. Explica que "al niño le pertenece, y el lo sabe, todo cuanto va corriendo vivo por el lomo del mundo: luz, agua y palabra cantada o cantable" (Scarpa, 2005, 279).

Consideramos materialmente como su pedagogía poética el conjunto de escritos, principalmente prosa (recados, elogios, etc.), pero también Poema de Chile, en los que realiza reflexiones pedagógicas. Esta idea se formó en vistas también a la constante preocupación por parte de la poeta de brindarle belleza al proceso educativo, como al vínculo entre maestro/a y niño/a; viendo una relación intrínseca en ellos, declara "la Pedagogía tiene su ápice, como toda ciencia, en la belleza perfecta. Esta, la escuela, es, por sobre todo, el reino de la belleza perfecta. Este es el reino de la poesía insigne. Hasta el que no cree cantar, aquí está cantando 
sin saberlo" (Scarpa, 2005, 275). Asimismo se despliega como una fuerza expresiva, de gran carácter visual, que va trazando en torno a las figuras de la maestra y el niño/a.

La idea de una pedagogía poética vendría siendo en el discurso mistraliano el desborde del lenguaje que se apodera del hablar técnico pedagógico y le brinda la posibilidad de hacerlo más plástico, atrayente y bello. Posibilitaría una forma diferente de relacionarse entre educador y educando, al darle espacio a la libertad en una relación recíproca de conocimiento, creación y ternura. Por esto, la maestra idónea para guiar a Niña Ciervo sería la que concebimos como madre/maestra. De la misma manera una pedagogía poética se presentaría más aprehensible en cuanto elabora imágenes, vinculando lo concreto con lo abstracto. Niña Ciervo sería en esta pedagogía poética una alegoría del proceso educativo, en ella se cifra la fantasía, la avidez por capturar las cosas bellas del mundo, el placer de la lectura. La experiencia del conocer se transforma en Niña Ciervo en una experiencia holística, creadora y alucinante. A continuación realizaremos una breve mención al Poema de Chile, desde donde emerge más claramente la figura del niño/a ciervo y en donde pone en práctica esta pedagogía poética.

El Poema de Chile propone un imaginario distinto de la Nación conformada desde un ángulo diferente, construyendo una narración otra de Chile, rica en diversidad y potencial crítico de la narraciones tradicionales y androcéntricas.

\section{Poema de Chile}

La crítica literaria reciente ha visto en Poema de Chile "un oficio de creación de patria" (Quezada, XLV), un cuestionamiento a la modernidad, una problematización de las identidades genéricas y minoritarias, un discurso ecológico. Todas estas lecturas, fruto de una nueva visión y revaloración del pensamiento mistraliano, coinciden en que es un texto de valor crítico fundamental. Para Ana Pizarro una de las motivaciones de Poema de Chile es "la necesidad de expresar y conformar al mismo tiempo el imaginario de una comunidad nacional o continental" (Pizarro, 2005, 63). Este es un proyecto compartido por poetas e intelectuales 
latinoamericanos que pretenden indagar o dar respuesta al complejo problema del origen, reflexión sobre cómo se construye la historia, los componentes culturales, el carácter nacional, en las profundas tensiones de un continente que se ha constituido heterogéneo.

Poema de Chile es una obra que Mistral lleva a cabo a lo largo de toda su vida fuera de Chile, la que se publica diez años después de su muerte. En ésta, Gabriela realiza un viaje de aprendizaje o (re)conocimiento por Chile en compañía de un niño-ciervo intentando hacer un rastreo de nuestra identidad chilena, nuestra historia, a partir de la particular visión de esta pareja tanto del paisaje como de la geografía humana. Soledad Falabella plantea que "en Poema de Chile tiene lugar un proceso de legitimación de un saber distinto, de aquello que tiende a ser tirado al sótano, de un discurso desde abajo: tierra, cuerpo originario, materno" (Falabella, 2003, 142). Concordamos con Falabella que en Poema de Chile Mistral está proponiendo otra forma de saber que emerge desde otro lugar, que como hemos expuesto de acuerdo a la pedagogía poética, concibe una visión más amplia sobre el mundo, poniendo en circulación la noción de diferencia como algo positivo.

En Poema de Chile Mistral despliega el deseo por recuperar un territorio en su dimensión tanto geográfica como espiritual; el país recobrado en la memoria creadora que reconstituye fragmentos de un espacio nostálgico no exento de crítica social y de las luchas que siempre alentó (como por ejemplo la de la reforma agraria). Olores, sonidos, texturas, nos van abriendo un panorama de nuestro país que le aleja de la forma tradicional de concebirlo. Se percibe en la relación establecida entre el niño-ciervo y la mama fantasma una nueva forma de vínculo madre-hijo/ maestra-estudiante, en la cual se hace valer el lazo simbólico frente al genético.

\section{Conclusiones}

Hemos logrado encontrar elementos inéditos de un discurso pedagógico en el interior de la obra mistraliana, ya sea de la poética como de su prosa, con lo que se abre un nuevo espacio posible de 
investigación. Esto de cierto modo, constituye el descubrimiento y la apertura de una área progresista acorde a las nuevas formas de comprensión del niño/a y del mundo del niño/ $a^{3}$; sobre todo, podríamos agregar, desde cierto ángulo, que lo anterior se vislumbra en el tema de la diversidad, de la diversidad de formas de conocer y de ser en el mundo, situación que hoy en pedagogía es un tema central, el cómo enfrentar o trabajar la diversidad, integrando la dimensión de género. Es en este espacio donde se instala niña ciervo.

Consideramos que la pedagogía poética y la figura de niña ciervo como alegoría del proceso de aprendizaje, desmitifica la manera tradicional de ver a Mistral como maestra, esa figura autoritaria, seria, severa, muy al estilo del antiguo billete de cinco mil pesos, mostrando aquí una faz diferente, de encantamiento del mundo en el proceso educativo, un proceso activo y de intercambio mutuo entre niño/a y maestro/a. Situación que queda patente como hemos mencionado, en el Poema de Chile, donde los personajes introducen nuevas lecturas sobre el saber y la educación, interrelacionadas con la conformación diversa de nuestro país.

La situación óptima del desarrollo integral del niño que ofrece Mistral en la propuesta pedagogía poética, aporta un sinnúmero de herramientas para el maestro/a, algunas que ya se trabajan en formas alternativas de pedagogía. Podemos mencionar entre las más interesantes e innovadoras de su pensamiento las siguientes; el interés por la subjetividad del niño/a en la idea de que posee una forma de conocimiento que le es propia; la utilización de todos los sentidos como punto crucial para comprender la belleza que nos entrega el mundo; la belleza o lo estético entendidos también como modos de conocimiento; la ocupación cada vez más común de lo visual y del mundo cotidiano en el aula; la introducción de la lectura como un placer; la integración del juego como una forma positiva de alentar el aprendizaje. Su discurso está atravesado por una perspectiva de género en la visión de la educación que manifiesta su postura vanguardista como intelectual y como educadora; integración muy adelantada para su época que se preocupa de concebir e integrar lo femenino como algo valorado y positivo, como esa otra forma de ser, que se asimila en este caso al ciervo y al niño/a. 
Consideramos que la propuesta educativa mistraliana es difícil que se produzca en nuestra enseñanza pública, por los problemas de presupuesto e infraestructura, pero también por un tema de currículum. Nos preguntamos, ¿qué es lo que se privilegia en la enseñanza? ¿Para qué estamos formando, es decir, cuál es la función que cumple ésta hoy en la sociedad? El hecho de que sea un factor económico el que determine el acceso a una educación de calidad, que se preocupa del desarrollo estético del niño/a (pues hay metodologías que se aplican en Chile cercanas a esta concepción de Mistral, por ejemplo, Montessori, Baldorf, que la autora conocía), es una cuestión que tenemos que asumir con responsabilidad social. Por esta razón efectivamente hemos comprobado que la pedagogía poética que sugerimos construye Mistral en sus múltiples escritos y en Poema de Chile, es una crítica a la educación y a la razón homogeneizadora, que deja fuera todo aquello que se considere bajo sus parámetros diferente (como lo femenino, lo mestizo, lo indígena), que no toma en cuenta la multiplicidad de formas en que se puede desarrollar un niño/a. Sin embargo, la poeta nos dice que también es parte de la voluntad del maestro realizar este proyecto, es decir, hace un llamado al encantamiento del maestro en su labor, pues también un punto crucial de su pedagogía poética es la conexión del maestro/a con la vida. Pensamos que en esta frase de Mistral se expresa esta conexión trascendental: "Los maestros que son personas sentadas en el medio de la vida" (Scarpa, 2005, 281). Gabriela Mistral sintetiza la responsabilidad ${ }^{4} \mathrm{y}$ al mismo tiempo la belleza que significa ser maestros, en una actividad que requiere de vocación, espíritu de sacrificio y servicio, en su fundamental compromiso con la vida (con todos las niñas ciervos) y por extensión con el presente y futuro de la Nación.

\section{Notas}

1 Licenciada en Arte, mención Teoría e Historia del Arte, Universidad de Chile; Estudiante de Máster Oficial Estudios Avanzados en Historia del Arte, Universidad de Barcelona.

2 La expresión es de ella.

3 Situación que ha visto en múltiples facetas de la poeta, como su sentido y conciencia ecológica muy adelantada a su época que se vislumbra en varios escritos así como en el Poema de Chile. 
4 Responsabilidad que exige una constante puesta al día, un cultivo intelectual, y un trabajo de reencantamiento diario para mantener vivo el espíritu de belleza que mueve y concita toda enseñanza.

\section{Bibliografía}

Alegría, Ciro. Gabriela Mistral íntima. Chile: Editorial Antártica S.A., 1998.

Calderón, Alfonso (comp.). Gabriela Mistral: Croquis mexicanos. Chile: Editorial Nascimento, 1978

Falabella, Soledad. ¿Qué será de Chile en el cielo? Poema de Chile de Gabriela Mistral. Santiago. Chile: Editorial LOM, 2003.

Olea, Raquel y Soledad Fariña Ed. Una palabra cómplice, encuentro con Gabriela Mistral. Chile: Editorial Cuarto Propio, 1997.

Pérez, Floridor (comp.). Gabriela Mistral: 50 prosas en El Mercurio 1921-1956. Santiago, Chile: Editorial El Mercurio-Aguilar, 2005.

Pizarro, Ana. Gabriela Mistral. El proyecto de Lucila. Chile: Editorial LOM, 2005.

Quezada, Jaime (comp.). Gabriela Mistral. Poesía y Prosa. Chile: Editorial Andrés Bello, 2001.

------. Escritos políticos. Gabriela Mistral. México: Fondo de Cultura Económica, 1994.

Scarpa, Roque Esteban (comp.). Gabriela Mistral. Magisterio y Niño. Chile: Editorial Andrés Bello, 2005.

------. Gabriela piensa en.... Santiago, Chile: Editorial Andrés Bello, 1978.

Sefchovich, Sara. Gabriela Mistral, en fuego y agua dibujada. México: Editorial Universidad Autónoma de México. D.F., 1997.

Vidal, Virginia. Gabriela Mistral y la juventud. Chile: Editorial Texido, 1994.

VV. AA. Gabriela Mistral a 50 años del Nóbel. Departamento de Programas Culturales -División de Cultura- Ministerio de Educación. Chile, 1997. 